\title{
Food Processing Technology and Packaging: A Case Study of Indian Cashew- nut Industry
}

\section{Patil PJ}

The Institute for Natural Resources, Kolhapur, India

${ }^{*}$ Corresponding author: Patil PJ, The Institute for Natural Resources, Kolhapur, India, Tel: 91+9975360901, E-mail: patilparashram9@gmail.com

Citation: Patil PJ (2016) Food Processing Technology and Packaging: A Case Study of Indian Cashew-nut Industry. J Nutr Health Sci 3(2): 204. doi: 10.15744/2393-9060.3.204

Received Date: March 23, 2016 Accepted Date: May 25, 2016 Published Date: May 27, 2016

\begin{abstract}
India is the global leader in world cashew business and cashew-nut industry is one of the important food processing industries in world. The most important problem of cashew nut processing industry is that is processing and packaging. Deficient processing reduce the quality of cashew kernel, the main problem is from the broken nuts which has lower price in market than entire cashew kernel and are not eligible for export. Cashew nut processing technology and packaging are the most important aspects that affect on nutrition value of cashew-nut. In order to protect nutrition content processing and packaging need to be taken care of it. India could maintain its monopoly in world cashew marker for long period of time by improving cashew nut processing and packaging technology. By doing this it will also contribute into food security.
\end{abstract}

Keywords: Cashew Processing; Technology; Packaging; Nutrition; Food

\section{Introduction}

India is the global leader in world cashew business and cashew-nut industry is one of the important food processing industries in world. However India is the largest producer, processor, exporter and importer eschew in the world. India is providing cashew to the rest of the world [1]. India is meeting world demand of cashew. India has a tremendous potential of cashew production and export to other countries. Every year India earns more than 2000 cores rupees through cashew trade. Cashew nut industry is one of the important small scale industries in the country which is playing significant role in rural development. World Bank and IMF recognized cashew-nut industry is one the important tool for poverty eradication at global level. It shows important of cashew business and its strong existence in India [2].

\section{Statement of the Problem}

The most important problem of cashew processing industry is that is processing and packaging. Bad processing reduce the quality of cashew kernel at large extent especially broken of cashew kernel which has very less price in market compare to whole cashew kernel and not eligible for export. On the other hand if there is no good packaging of cashew kernel will get moisture which destroy test of it. International trade of cashew-nut is depend of two things one is cashew nut processing and other is packaging. This study has strong relevance because cashew-nut industry is the labour oriented, where processing technology is not playing important role because $95 \%$ processing work is manual. Hence processing work was depending on physical performance of worker which makes presence of large workforce inevitable. There are many cashew nut processing units closed because they are not getting sufficient work force. However due to advancement in technology slowly this picture is changing and processing work get improve. Therefore it is interesting to explore all the aspects in context of cashew processing and packaging of cashew business [3].

\section{Review of Literature}

Dr. Yadhav, on his report Economic Analysis of Cashew had discussed about existing supply chain of Indian cashew-nut industry. The Market for Cashew-nut in India' prepared by Ghana Export Promotional Council, analyzed market for cashew-nut in India [4]. It mentioned that India is major center for cashew-nut in the world. 'Integrated Production Practices of Cashew in Asia' this book is edited by Papademtriou, et al. in it explained about cashew production practices which are in Asian cashew producing setups [5]. Sandhu, in 'An Econometric Analysis of Indian Export Share of Cashew Kernel in the world' shows India's export share of cashew in total world cashew export has been reduced due to keen competition in production technology and processing 
coupled with low units of value offered by the competing economies [6]. Walkar, et al. in his article 'Performance of Cashew Export from India', it has mentioned India had a monopolistic position in the international cashew market but more competition coming from the countries like Brazil, Vietnam and Mozambique etc [7,8].

\section{Objectives of the Study}

The following are the specific objective of the study.

(1) To identify problems of cashew nut processing and use of processing technology,

(2) To study problems of cashew kernel packaging,

(3) To study evolution of cashew nut processing technology over the year and its impact on final product.

\section{Hypothesis of the Study}

The following is the hypothesis of the study.

(1) There is impact of cashew nut processing technology on cashew kernel.

\section{Research Methodology}

This is the explanatory study on Indian cashew-nut industry. It deals with the different component of cashew nut processing and its quality control practices. It tried see impact of cashew processing technology on final product. The present research work is mainly based on observation and secondary data. It has make detailed analysis of entire cashew nut processing methods and its quality control practices in order to understand its impact on cashew kernel [9].

\section{Cashew processing and its Technology}

There is systematic process has to be followed while making out cashew kernel from hard cashew-nut. Cashew processing is combination of suitable machinery and skilled labour which produce very good final product [10]. Use of machinery in cashew nut processing work make job simple and effective. Cashew processing techniques make impact of overall final product hence processing steps has its own importance. Following is the actual cashew processing methodology.

\section{Cleaning}

Cashew-nuts are collected from open farm hence it consists of dusts and foreign matters that has to be eradicated. Hence first step is to clean cashew-nut and eliminate dust and foreign matter thus it will not be present in further processing. It it is not clean well it is bound to make impact on final production.

\section{Roasting}

Processing of cashew-nuts refers to the conversion of raw cashew-nuts in shell to its blanched graded kernel form. Roasting of cashew-nut has been evolved in stages over the period of time. Following are the methods by which roasting has been done of cashew-nut.

Drum Roasting: This is one of the oldest and more widely used methods. The nuts are fed into a rotating red hot drum which will ignite the shell maintaining its temperature because of the burning of the shell liquid. The drum is kept in rotation for 3-4 minutes and the roasted nuts are discharged from the lower end of the drum and immediately covered by ash after sprayed with little water, so as to absorb the oil on the surface. This facilitates the removal of the remaining oil on the shell. Due to draw backs of the method is superseded by oil bath roasting, (Cashew and Coca Development Cochin).

Oil Bath Roasting: In this method conditioned nuts are passed through CNSL bath heated to 170-2000C by conveyer buckets for 1-2 minutes during which period the shell gets heated rupturing the wall and releasing the oil into the bath. The oil is recovered by continuous over flow arrangement. The roasted nuts are centrifuged to remove adhering oil, cooled and shelled by hand and leg operated shelling machines. The kernel with the adhering testa is scooped out using a sharp needle. ((Cashew and Coca Development Cochin).

Steam Roasting: The raw nuts are steam cooked at about 120-140 lbs/sq inch pressure. Shell oil can be extracted in later stages by crushing. The nuts are shelled by hand and leg operated shelling machines. (Cashew and Coca Development Cochin). At present this method of cashew roasting has been used in practices.

A general comparison of the above three methods the steam roasting methods (Figure 1) is best it is because it is environment friendly and there is good impact on final product. It does not deteriorate quality of the cashew kernel while making process. 


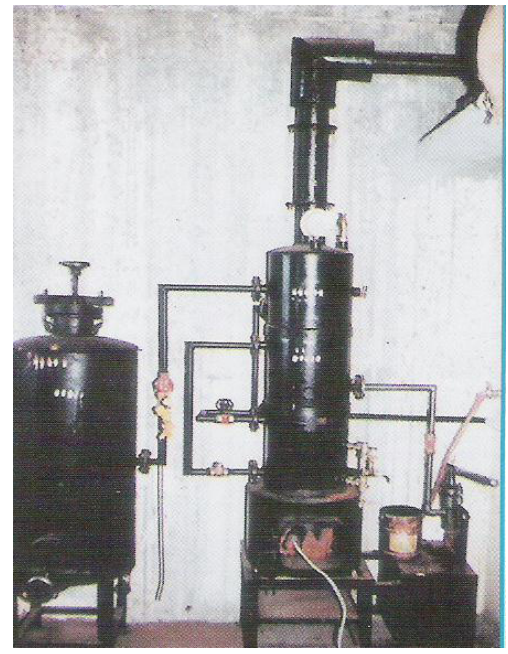

Figure 1: Steam Roasting

\section{Cutting}

After roasting of cashew next process is of cutting. In this process cashew-nut is cut and remove the cashew kernel.

With the help of cashew cutter cashew cutting is done (Figure 2). It helps to make whole cashew kernel which has great demand in market. Removed cashew-nut shell will be raw material for making cashew-nut shell liquid oil.

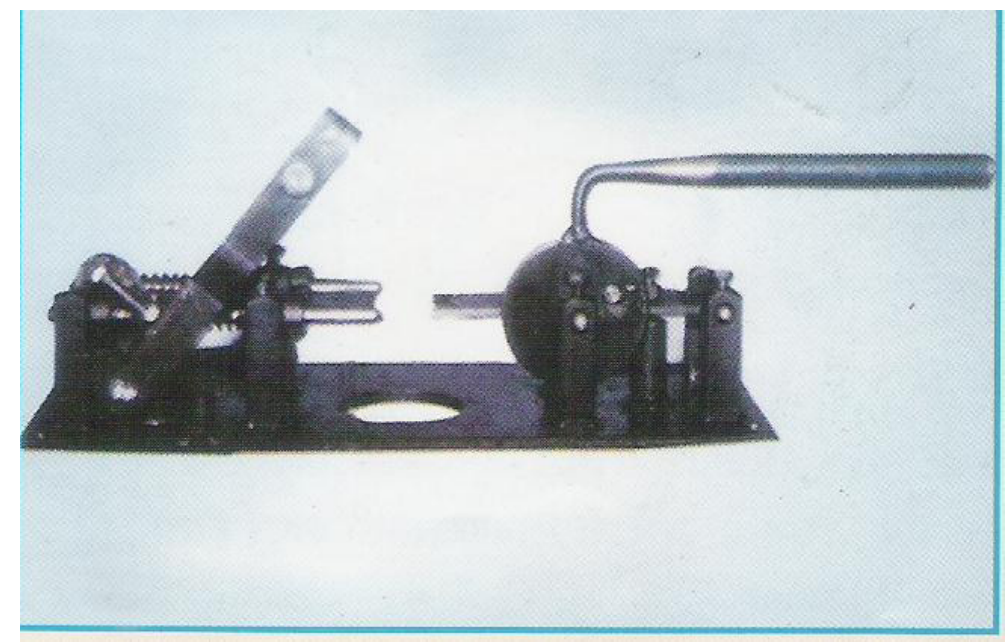

Figure 2: Cashew Cutter

\section{Pre- Grading}

It is process of separating mainly the whole from the broken kernels and sometimes separating the different size group of whole kernels before it is sending for drying (Figure 3).

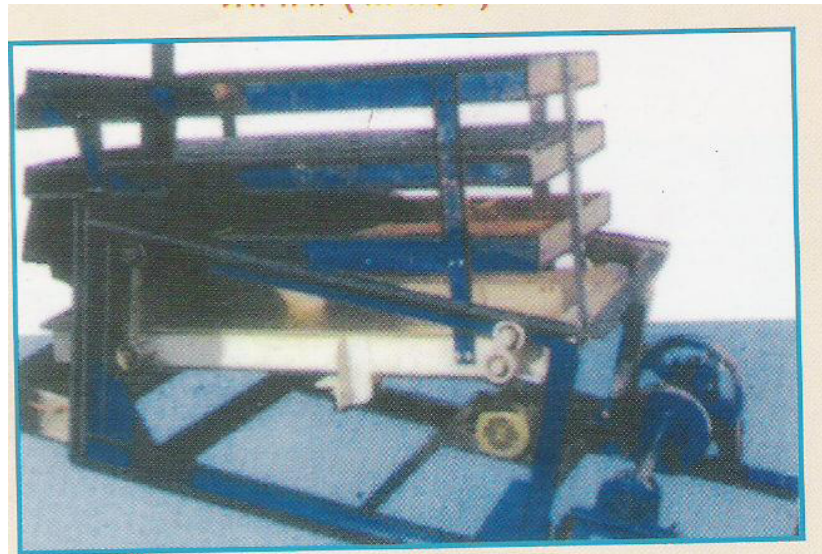

Figure 3: Grading Machine 


\section{Drying}

The kernels after they are removed from the shells have to be dried in order to loosen the red skin attached to the kernel for easy peeling.

Cashew dryer machine (Figure 4) helps to remove moisture from cashew kernel so that it does not affect on it. If cashew kernel is not properly dried it will get deteriorated very soon.

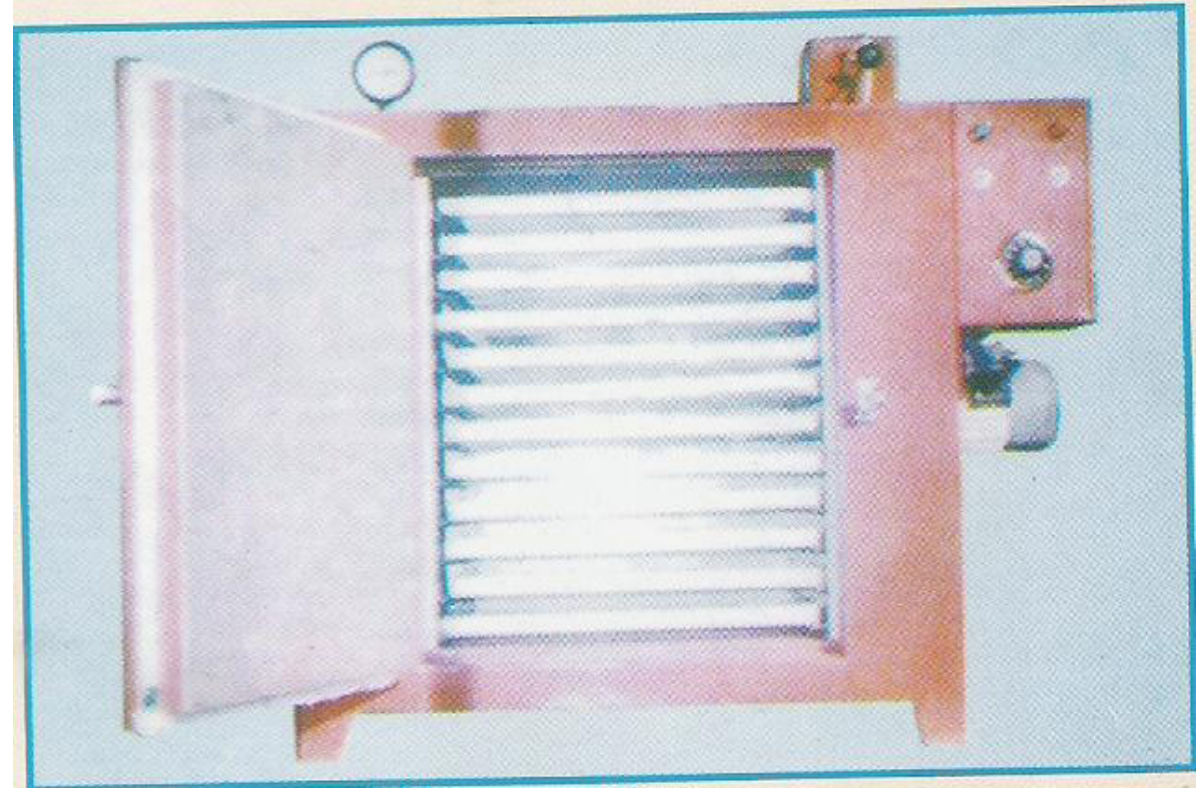

Figure 4: Cashew Dryer

\section{Peeling}

In the peeling process the testa which is loosely attached to the kernel is removed, although a small amount of kernels may have already lost the testa during the previous operations.

Peeling work (Figure 5) is important because it determines the quality of final product, requiring hygienic conditions and quick turnaround of large quantities of kernels.

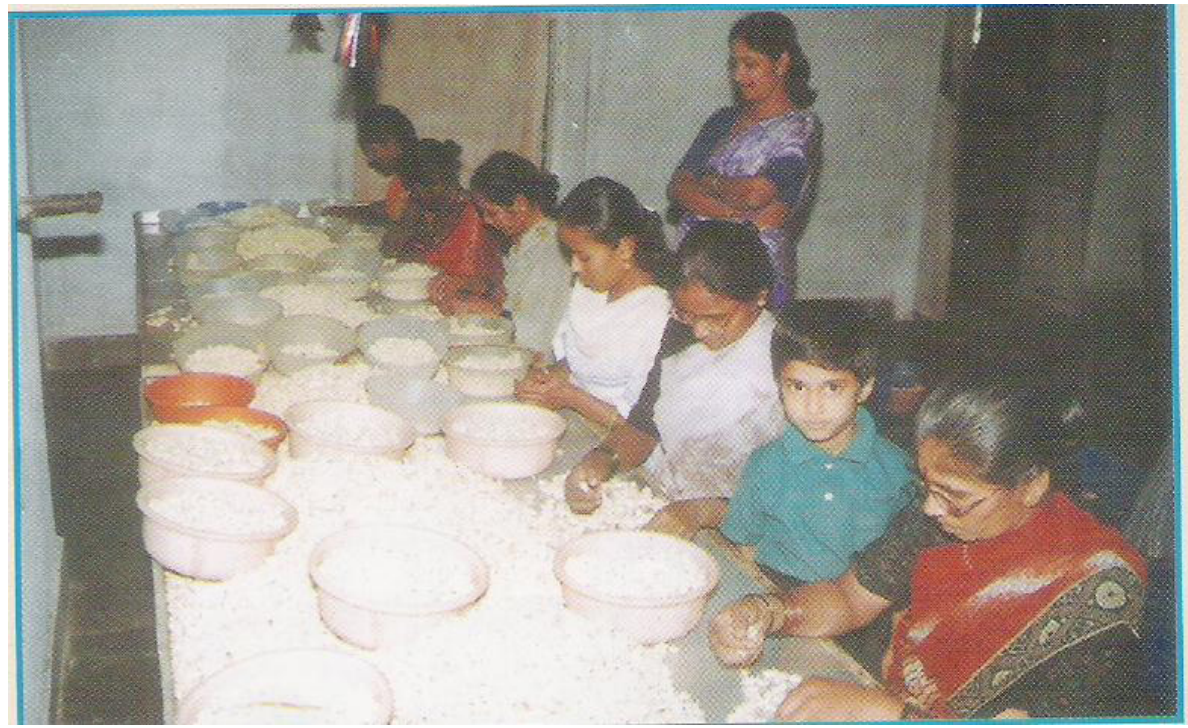

Figure 5: Peeling Work Performed by Workers

\section{Grading}

Cashew kernels are graded into white/scorched wholes, pieces, splits, butts, etc., depending on the shape size \& color of the kernel. It has been prescribes 33 different grades of cashew kernels. Only 26 grades are commercially available and exported [11]. They are as follows. 
(1) W - 180, is the 'King of Cashew' - They are larger in size and very expensive.

(2) W - 210, are popularly known as 'Jumbo 'nuts.

(3) $\mathrm{W}-240$, it is an attractive grade which is reasonably priced.

(4) W - 320, are the most popular among cashew kernels and highest in terms of availability, worldwide.

(5) W - 450, are the smallest and cheapest white whole kernels and hence the favorite among low priced whole grades.

(6) Scorched wholes are another grade of cashew kernels, which have a slight brown colour due to longer roasting. They have all the other characteristics of white kernels and have the same nutritional qualities. Butts, splits and pieces are priced lower and are ideal for cooking, preparation of sweets and savoury snacks. As final price of the product is depend on individual grade of cashew kernel it needs to be taken optimum care while making grading. Improper grading may leads to inappropriate price for product.

\section{Re-humidification}

Before sending cashew kernel to packaging there is need to make re-humidification of it. .It is important that the moisture content of kernels rise from $3 \%$ up to around 5\%. This is results in making the kernels less fragile, thus reducing the risk of breakage during transport.

\section{Packaging}

In order to reacher safely cashew to customer need to make good packaging of it. It consists with Vacuumised and flushed with Nitrogen. This is because cashew requires special treatment when packaging. It has to be in an "inert atmosphere". An inert atmosphere is created by removal of air which makes the inside of the container free of oxygen. This can be done by having a vacuum pack or infusing it with an inert gas, such as nitrogen (Figure 6).

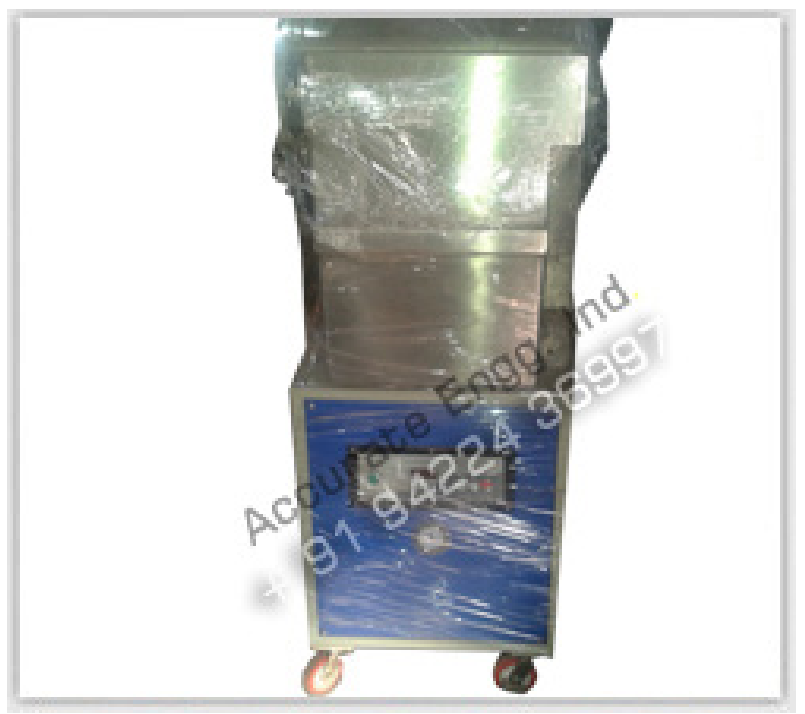

Figure 6: Cashew Kernel Packaging Machine

Good packaging increase life of the product. And there are machine available to help to make proper packaging of cashew kernel. Packaging is one of important input to increase quality of cashew kernel. Cashew kernels in bulk are packed in four gallon prime tins with a net weight of $11.34 \mathrm{Kg}$ (Or $25 \mathrm{lbs}$ ) in each tin. The filled tins are then vacuumised and filled with carbon-di-oxide gas and sealed. Two such tins of the same grade are packed in a carton for export. The net weight of each carton is thus $22.68 \mathrm{Kg}$. (50 lbs.). Some manufacturers also pack in tins of $10 \mathrm{~kg}$ net to suit the requirements of buyers in certain markets. Recently, some exporters have started using flexible packs instead of tins as many buyers opt for new generation flexible packs.

\section{Conclusion}

Processing of cashew-nut is systematic which himself consist of quality control practices. Quality of cashew kernel starting to affect since from cashew harvesting practices. If the cashew harvesting is not properly done it make impact on further processing of it. Over a period of time cashew nut processing methods has been evolved. Due to progress in the technology it makes positive impact on final product. There is increase in proportion of whole cashew kernel. Cashew processing technology and packaging are the most important aspects that effect on nutrition value of cashew-nut. In order to protect nutrition content processing and packaging need to be taken care of it. Processing is the optimum combination of appropriate processing machinery and skilled labour [1]. Cashew can be great source of food security having rich content of nutrition which is required for good health. It has zero cholesterol effect [12]. Hence it is one of the most demanded food in international market. Hence its processing has to be modified in great extent so that wastage of cashew kernel while processing can be reduce down. Existing processing methodology is good but has big scope for improvement. Especially India who is global leader in cashew business must take leading role in it. 


\section{References}

1. Patil (2012) Problems and Prospects of Cashew-nut Industry of Kolhapur District. Shivaji University, Kolhapur, India.

2. Steven J (1994) Private Trader Response to Market Liberalizations in Tanzania’s Cashew Nut Industry. The World Bank Agricultural and Natural Resources Department Agricultural Policies Division.

3. Brijesh K (OlamExpots) (2004) Supply and Demand Dynamics 2004 Beyond Raw Cashew nuts and Kernels.

4. Mole PN (2000) An Economic Analysis of Smallholder Cashew Development Mozambique’s Northern Provinces of Nampula. Michigan State University.

5. Minas K, Papademtriou, Herath EM (1998) Integrated Production Practices of Cashew in Asia. Food and Agricultures Organization of the United Nations, Regional Office for Asia and the Pacific Bangkok, Thailand.

6. Sandhu HK (1982) An Econometric Analysis of Indian Export Share of Cashew Kernel in the world trade. 37: 300-05.

7. Mcmillan M, Roderick D, Welch KH (2002) When Economic Reform Goes Wrong: Cashew in Mozambique. National Bureau of Economic Research 1050 Massachusetts Avenue Cambridge, MA02138.

8. Walkar, et.al. (2005) Performance of Cashew Export from India.

9. Hari N (2004) Marketing Nutrition - for Cashew. Indian Cashew Cashew Convention 2004, Raddission White Sands Ressorts Goa, In continuation of the konkan cashew festive 2003.

10. Mahajan SS, Patil (2009) Role of Cashew nut Industry in Development of Hilly Region In Kolhapur District. National Conference on Development of Hilly Region: The Problems and Potentials,

11. Manojkuma M (2004) Managing the Price for Cashew. Indian Cashew Convention 2004, Radission White Sands Ressort Goa, In continutation of the konkan cashew festival 2003.

12. Praveen KV (2004) Consumer Perspective on Cashew Procurement. Indian Cashew Convention 2004, Raddission White Sands Ressorts Goa, In continuation of konkan cashew festival 2003. 